\title{
Practice Spotlight: Pharmacists in a Centre for Ambulatory Care Education
}

\author{
Lisa McCarthy, BScPhm, PharmD, MSc \\ Clinician Scientist, Women's College Hospital \\ Assistant Professor, Leslie Dan Faculty of Pharmacy \\ University of Toronto \\ Anna Wdowczyk, BScPhm \\ Pharmacist \\ Women's College Hospital \\ Natalie Crown, BScPharm, PharmD \\ Clinician Educator, Women's College Hospital \\ Assistant Professor, Leslie Dan Faculty of Pharmacy \\ University of Toronto
}

$\mathrm{T}$

The Centre for Ambulatory Care Education was established

by Women's College Hospital and the University of Toronto as an extra-departmental unit to improve ambulatory care education among health professionals. Women's College Hospital, with its unique mandate as Ontario's only standalone academic ambulatory care hospital, is a natural home for the Centre. The first initiative undertaken by the Centre for Ambulatory Care Education was creation of the Complex Care Clinic. Other ambulatory internal medicine clinics exist in Ontario, but this Clinic is distinct because of the interprofessional nature of the team and because the team provides ambulatory care education to learners from a variety of health care professions, while also providing care to patients with complex conditions.

The Complex Care Clinic began operations in July 2011. At the time of writing, in May 2012, it operates 3 half-days weekly, and in July 2012, the schedule will expand to 4 halfdays weekly. Each clinic begins with a small-group educational session or case discussion covering various internal medicine topics, attended by learners from participating health care disciplines (e.g., medicine, pharmacy, social work). Many of these sessions are cofacilitated by an internal medicine physician and a pharmacist.

Lisa McCarthy and Anna Wdowczyk partnered to develop the role of the pharmacist on the Complex Care Clinic team, and Natalie Crown joined the team in March 2012. The successful integration of these 3 pharmacists was facilitated by the strategic contribution of 0.3 full-time equivalent of pharmacist time by Pharmacy Services. Now, as the Complex Care Clinic expands, securing funding to support the pharmacist has been identified as essential to the success of the program.

Since the clinic's opening, the 3 pharmacists have collectively provided pharmaceutical care to more than 100 patients. In addition to their role as direct patient care providers, the pharmacists have helped to develop policies and procedures for the clinic and have provided guidance on workload documentation. The pharmacists are conducting rapid plan-dostudy-act cycles as they explore options for a medication reconciliation strategy that will involve community pharmacists.

Most of the patients referred to the Complex Care Clinic have seen multiple physicians, are taking multiple medications, and are at risk of clinical deterioration and admission to hospital. The clinic's interprofessional team consists of internal medicine physicians and residents, pharmacists, social workers, occupational therapists, physiotherapists, respiratory therapists, a nurse, and a home care case coordinator. The team partners with patients to develop comprehensive care plans that support self-management. Patient referrals may entail a one-time consultation or, more commonly, coordinated care on an ongoing basis.

Patients access the program through referral by a physician. One of the pharmacists is always present during clinic hours and is thus available to review cases with the internist and resident. If a one-to-one pharmacist consultation is needed, a 15- to 60-min visit is booked with the pharmacist, and the number of follow-up visits is individualized.

In winter 2012, the Complex Care Clinic welcomed its first pharmacy resident for a rotation, with great success. As a result, the Clinic will be a core longitudinal rotation for the new pharmacy residency program being launched by Women's College Hospital in July 2012. Additionally, cases from the Complex Care Clinic have been adapted to teach knowledge and skills to pharmacy students in the combined BScPhm/PharmD program at the Leslie Dan Faculty of Pharmacy, University of Toronto.

An unexpected element that the pharmacists have brought to the Complex Care Clinic team is their perspective as 
experienced ambulatory health care providers. In contrast, staff physicians and medical residents are accustomed to providing care through inpatient services. As such, the pharmacists often assume patient advocacy roles, helping the team to adapt care plans from the inpatient setting to what works for patients living in the community.

As noted by the Commission on the Reform of Ontario's Public Services, "About one per cent of Ontario's population accounts for 49 per cent of hospital and home care costs, and 10 per cent of the population accounts for 95 per cent of such costs, according to a 2010 study by the Canadian Health Services Research Group". ${ }^{1}$ Hospital readmission rates are high, and those with multiple chronic conditions are overrepresented among readmitted patients. Reducing acute care readmission rates and avoidable emergency department visits is a top priority for the improvement and sustainability of the Canadian health system. The Complex Care Clinic is a model of care that is receiving much attention in the province as it strives to provide integrated care for medically complex patients in an ambulatory setting. The pharmacists of the Complex Care Clinic are showcasing how our profession can contribute to patient care at Women's College Hospital, a hospital that is designed to keep people out of hospital.

\section{Reference}

1. Chapter 5: Health. In: Public services for Ontarians: a path to sustainability and excellence. Toronto $(\mathrm{ON})$ : Commission on the Reform of Ontario's Public Services; 2012 [cited 2012 Mar 1]. Available from: www.fin.gov. on.ca/en/reformcommission/chapters/ch5.html

The Practice Spotlight series highlights the accomplishments of Canadian pharmacists with unique practices in hospitals and related health care settings. If you have a unique or innovative practice, or you know someone else who should be profiled, please submit your contact information to Mary Ensom, Editor of CJHP (cjhpedit@cshp.ca), and one of our Associate Editors will be in touch with you. 